\title{
Increasing Boswellia sacra seeds' germination viability and genetic variability utilizing various methods
}

\author{
Benjamin T. Swartout ${ }^{1,2}$ and Elaine Solowey ${ }^{1 *}$ \\ ${ }^{1}$ Arava Institute for Environmental Studies, Israel. \\ ${ }^{2}$ United States Fulbright Commission, USA. \\ Accepted 14 June, 2018
}

\begin{abstract}
The medicinally and historically significant plant species Boswellia sacra, shown to be effective in addressing numerous illnesses and stabilizing desertification in arid areas, has been noted for having an extremely low germination rate. The low rate of genetic variation among wild stands, which is leading to a possible genetic bottleneck, is exacerbated by the common practice of vegetative propagation through tree cuttings in cultivated stands, which produces clones. Stimulation of seeds to germinate under various conditions at Kibbutz Ketura, Israel was attempted in order to increase genetic variability. Seeds were collected from three source locations and screened via sink tests to identify viable seeds as those that were heavy enough to sink in water. The greatest amount of viable seeds came from a tree in Kibbutz Naot Smadar, which was $400 \mathrm{~m}$ above sea level and had a higher germination rate (by a factor of four) than those from trees at elevations much closer to sea level. This conspicuous correlation is discussed as a reason for future research to further understand causes and ways of addressing the extraordinarily low regeneration rate of both wild and cultivated stands.
\end{abstract}

Keywords: Germination, Boswellia sacra, vegetative propagation, bottleneck.

${ }^{*}$ Corresponding author. E-mail: entsolowey@gmail.com.

\section{INTRODUCTION}

Belonging to the endemic genus Boswellia (family Burseraceae), B. sacra, commonly known as Frankincense, is a medium sized tree and is medicinally and historically significant with potential for stabilizing and reclaiming land threatened by desertification (Bowen, 1988; Lemenih and Teketay, 2004). Studies have highlighted an extremely low germination rate $(<10 \%)$, slow seedling growth rate, and difficulty regenerating Boswellia species in both wild and cultivated stands due to intensive tapping to harvest resin, human-induced fire, overgrazing, low genetic variability, lack of dormancy and climatic anomalies (Coppi, 2010; Negussie et al., 2008). These trees have made important contributions to the field of medicine from ancient times to modern research due to a multiplicity of medicinal effects of the tree products including anti-inflammatory, anti-oxidant, anti- ulcer, anti-arthritic, anti-asthmatic, anti-artherosclerotic, anti-cancer, anti-diarrhoeal, hepatoprotective, antimicrobial, anti-hyperglycemic, diuretic and analgesic influences (Navdeep et al., 2013). Currently much of the propagation of $B$. sacra is occurring through vegetative means, which results in genetic clones of trees and potential genetic bottlenecking. This is evidenced in the common issue of exceptionally low seed viability and decreasing genetic resources among the stands of this species (Eslamieh, 2011).

The aim of this research project was to explore how to increase the germination rate of $B$. sacra seeds through manipulation of growth and pollination conditions and to discover the underlying reasons for the low germination rates by other methods as well as laboratory analysis of the seeds. 
This study took place on Kibbutz (K.) Ketura in the greenhouses, laboratory, and experimental orchards in the Arava Valley of Israel (IL) using seeds from trees in K. Almog, IL, K. Naot Smadar, IL, and those collected in 2015 from the K. Ketura orchards. The trees in Israel are not native but were cultivated and esteemed in ancient Israel in Biblical times. The tree in K. Naot Smadar is a clone of the largest tree in the K. Ketura orchards, produced through vegetative propagation of tree cuttings. There has also been research showing the dangerously low genetic variation of $B$. sacra populations isolated in the wild stands of Oman (Coppi et al., 2010). To address the issue of the lack of genetic diversity in future generations of seeds, as well as the characteristic bisexual perfect flowers (which could be self-sterile as a result of low variability), the trees in the K. Ketura orchard were hand pollinated with pollen from $B$. nana trees of a farm near Be'er Tuvia, IL (Coppi, 2010).

\section{MATERIALS AND METHODS}

Preliminary studies for this research carried out during the Fall 2015 Semester at the Arava Institute for Environmental Studies in Kibbutz Ketura revealed that $1 \%$ of the seeds from trees in the $\mathrm{K}$. Ketura orchard had an embryo inside; the rest were empty shells. Therefore, sink tests were conducted on all of the seeds used in the various trials of this research experiment to examine which seeds sank because they contained embryos. In order to mimic the naturally more humid coastal mountain growth environs, which can be affected by seasonal southwest monsoons from the Arabian Sea, some trials were conducted using terrariums in the K. Ketura greenhouse (Mosti et al., 2012). In addition to control sets of seeds being planted in open air trays, another trial utilized $B$. sacra leaf litter in an attempt to lower the $\mathrm{pH}$ of the water to 5.5 , which has been shown to stimulate nutrient absorption and germination (Eslamieh, 2011). This study's hypothesis was that the greatest germination rate and most rapid sprouting would be observed in the leaf litter trial, followed by the next greatest in the trials utilizing a terrarium.

This study was conducted to determine which growing conditions would be conducive to the germination of $B$. sacra seeds collected from the experimental orchard of K. Ketura, the K. Almog Tree Farm, and K. Naot Smadar. In order to minimize the percentage of included seeds without an embryo, before planting any of the seeds used in the experiment, they were placed in water and only the ones which sank within five minutes were deemed viable. The viable seeds were then removed from the glass sink test container using tweezers and placed in a separate glass container (cleaned coffee jar) to continue soaking in water for $24 \mathrm{~h}$. The planting method used in all variations of the experiment consisted of surface sowing the seeds $\sim 1 \mathrm{~mm}$ deep in planting trays of Shoham professional potting soil, which was well moistened with the hose from the greenhouse set on a mist setting before and after sowing the seeds. The first three trials were conducted in open air trays, the fourth and fifth in a terrarium (with the purpose of regulating humidity to mimic the native more humid coastal mountain regions), and the sixth set utilized leaf litter of Boswellia sacra, also in an attempt to mimic the natural sprouting environment (Eslamieh, 2011). The hybridization of trees in the orchard with $B$. nana pollen, using a clean \#2 paint brush, began during the second week of May 2016.
The first control set of 50 seeds from K. Ketura were sown into open air trays and watered daily with the hose from the green house set to mist without any humidity varying conditions. The 50 seeds of the second set surface sown into open air trays were from K. Almog Tree Farm, and were treated in the same fashion as the first set. A third set sown in open air trays were from K. Naot Smadar, and consisted of 130 seeds that were deemed viable through the screening process of a sink test. A fourth set of 25 seeds from K. Ketura were sown using the same method, except they were placed in a covered glass terrarium which had dimensions of $58.5 \mathrm{~cm} \times 24 \mathrm{~cm} \times 34 \mathrm{~cm}$. A fifth set of 25 seeds from K. Naot Smadar were sown on a different side in the same glass terrarium, and labeled differently. The sixth set of 50 seeds from K. Naot Smadar were planted in an open air tray of the same soil and covered with a $\sim 2 \mathrm{~cm}$ thin layer of $B$. sacra leaf litter which was collected from cuttings of the four largest trees in the greenhouse and placed on top of the seeds in a manner that covered approximately $70 \%$ of the tray by surface area.

Of course the germination rate of the seeds would be registered by the rate of germination per set of seeds rather then by the average germination rate overall.

\section{RESULTS}

This research attempted to induce and stimulate germination of $B$. sacra seeds utilizing the methods described above. All of the seeds planted and considered in the trials were determined to be viable and known to have an embryo through sink tests. As depicted in Figure 1 , both the seed sets from K. Ketura and from K. Almog had four out of 100 seeds sink, whereas 17 out of 100 seeds sank from those collected in K. Naot Smadar. The seeds collected from K. Naot Smadar are from a tree which is a clone of the oldest tree at K. Ketura and were identical in size, shape and color to those harvested at $\mathrm{K}$. Ketura. The seeds clusters however were more abundant and, of course, the biggest difference was the increased number of seeds with embryos. While a single example is not enough to support a theory, it would seem to indicate that the problem behind the lack of viable embryos is not one of self-sterility but is perhaps due to environmental influences and conditions.

The seeds from the tree in K. Naot Smadar had a much greater percentage of viable seeds with embryos than the other two locations. Out of the first, second and third sets of seeds determined to be viable through the sink test and sown in open air trays, Figure 2 illustrates that K. Naot Smadar also had the greatest germination rate $(54 \%)$ of the seeds known to be viable.

It is important to note that this does not mean the tree from K. Naot Smadar had a total germination rate of $54 \%$, as it took 800 seeds going through the sink test in order to plant the 130 seeds used in the experiment. Therefore, the actual germination rate of the seeds in third set, which were from K. Naot Smadar is $8.875 \%$. The sets of seeds sown in the open air trays yielded the highest results by far, while none of the fourth set seeds from $\mathrm{K}$. Ketura, which were sown in the terrarium sprouted, and 


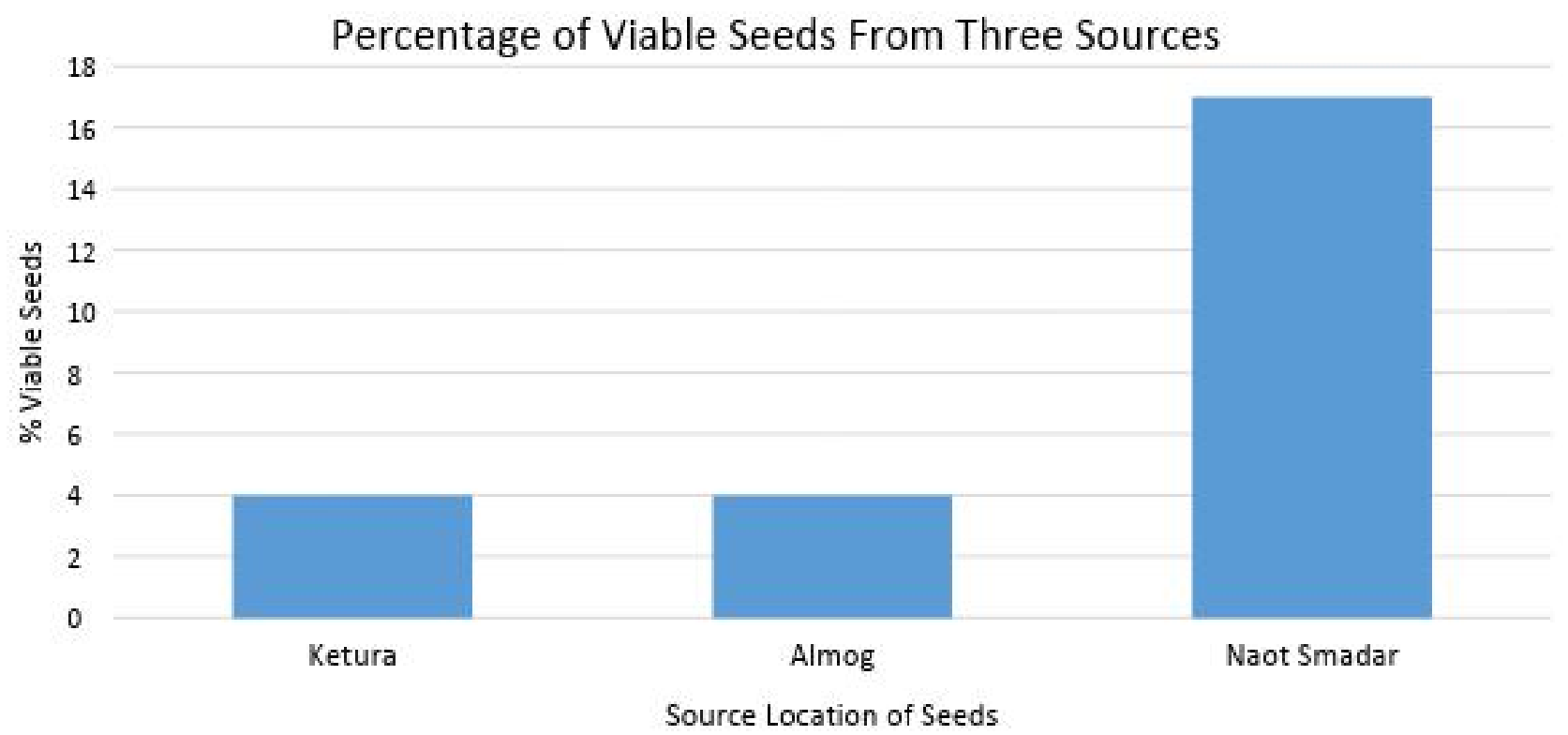

Figure 1. Bar chart showing K. Naot Smadar had the greatest the percentage of viable seeds out of the three source locations.

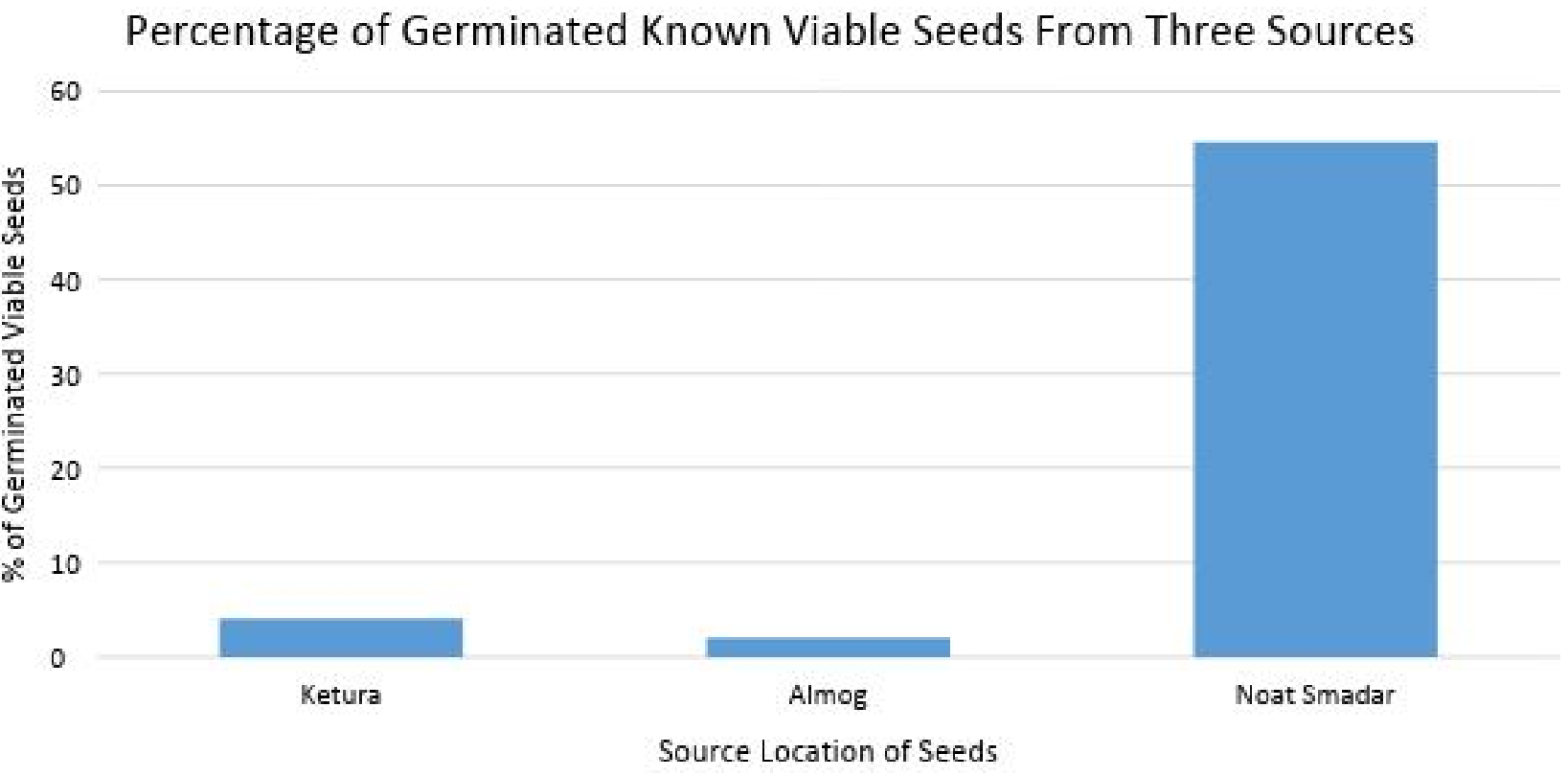

Figure 2. Bar chart showing K. Naot Smadar had the greatest percentage of germination among the seeds determined to be viable.

11 of the fifth set of seeds from K. Naot Smadar sprouted (a $44 \%$ germination rate of the known viable seeds). The sixth set of seeds from K. Naot Smadar yielded a germination rate of $14 \%$ ( 7 out of 50 seeds known to be viable sprouted from the tray covered in leaf litter). Figure 3 shows the seedlings from the third set of seeds.
The seeds used in these experiments came from source locations that are at different elevations, as shown in Figure 4.

The trees from K. Almog are less than $200 \mathrm{~m}$ below sea level, those from K. Ketura are just above sea level, and the one in K. Naot Smadar $400 \mathrm{~m}$ above sea level. 


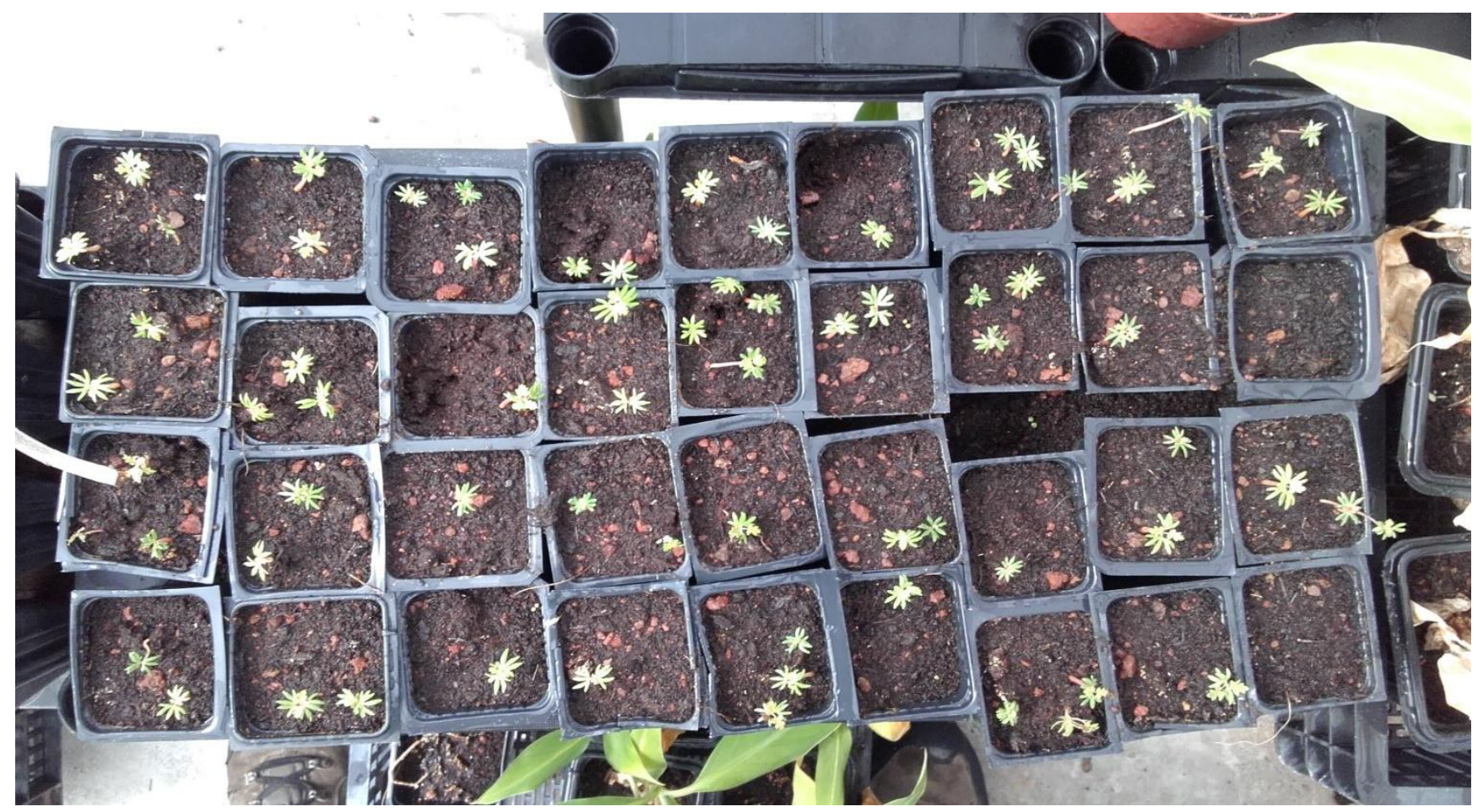

Figure 3. Seedlings from K. Naot Smadar in the K. Ketura Greenhouse after 14 days.

\section{Elevation of Each Source Location}

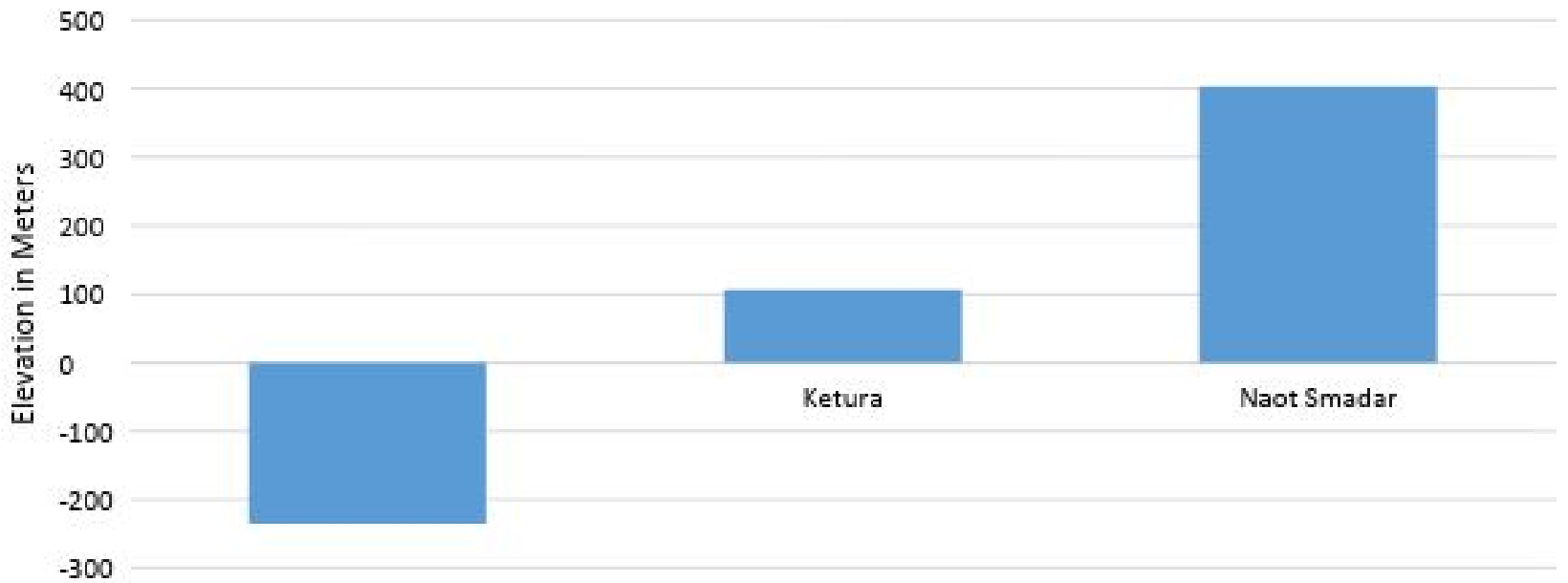

Figure 4. Bar chart depicting the elevation in meters of each source location with zero representing sea level.

\section{DISCUSSION}

This research was conducted with the objective of determining suitable conditions for the germination of Boswellia sacra seeds. Given that just two out of the seven trees at K. Ketura are mature enough to produce seeds, the experiment also included sets of seeds of one tree at K. Naot Smadar (which is a genetic clone of the trees at K. Ketura), and sets of seeds from multiple trees at the K. Almog Tree Farm, some of which are also genetically identical to the $\mathrm{K}$. Ketura trees. Under the circumstances of the K. Ketura greenhouse, the results showed that the method of open air tray surface sowing in Shoham professional potting soil, which is the standard 
used in that greenhouse, yielded the highest percentage of germinated seeds. The hypothesis that the leaf litter method and utilization of a terrarium would result in a greater germination rate and more rapid sprouting than the control was disproven within the conditions of this experiment. The seeds from K. Naot Smadar had a higher germination rate than those from $\mathrm{K}$. Ketura and $\mathrm{K}$. Almog by a factor greater than four ( $17 \%$ as compared to 4 and $2 \%$ respectively). However, this percentage is not the total germination rate, as it only included those seeds known to be viable through the sink test screening process in which seeds without an embryo floated, because they were lighter than water, whereas seeds with an embryo were heavy enough to sink. The actual total germination rate of seeds from K. Naot Smadar was calculated to be $8.875 \%$ which is consistent with the "often less than 10\%" germination rate announced in other studies (Eslamieh, 2010).

Observing the stark differences between the germination rates of the trees from the three source locations, the elevation above sea level was examined and found to be in correlation with the germination rate. That is, the tree in K. Naot Smadar is at a considerably greater altitude of 400 meters above sea level than the trees in the K. Ketura orchard (100 meters above sea level) and the trees at the K. Almog Tree Farm (approx. $200 \mathrm{~m}$ below sea level). As a major consideration when designing the experiment was to mimic the natural sprouting environment of the seeds through using leaf litter and terrariums to resemble the more humid coastal mountain regions of Yemen and Oman, it was not so surprising to find field investigations in that area revealed that altitude showed an effect on the regeneration rate of wild stand of $B$. sacra (Rafaelli, 2003). Indeed, while also not very genetically diverse, the "Wadi Dowkah Frankincense Park" which was recognized as a World Heritage Site by UNESCO in 2000 (World Heritage, 2016), currently has an ongoing program of germplasm conservation and restoration, and is "considered as the most representative Frankincense site in Oman" (Coppi et al., 2010). This park is at an elevation of 680 to $550 \mathrm{~m}$ above sea level, spans for 6 to $7 \mathrm{~km}^{2}$, and contains about 1,200 trees, some of which are centenarian, and noted as showing "an impressive branching architecture" as they branch very close to ground level (Raffaelli, 2006). Other more sparse, stunted, and scrubby $B$. sacra populations have been surveyed at elevations of around $18 \mathrm{~m}$ above sea level (Raffaelli et al., 2003). While other factors affect the health and regeneration of $B$. sacra populations such as humidity, geology and topography of surrounding mountains, weather patterns, presence of pollinators and human factors like cutting foliage for goat fodder, elevation plays a part in connection with all of these elements (Raffaelli, 2006).

The tree at K. Naot Smadar is in close proximity to the winery and dairy building as well as many other species of plants, which attract pollinators and assist in the production of a unique microclimate that has protection from harsh heat and stand storms. In contrast, K. Almog Tree Farm is located on top of a small hill near Jericho with very little protection aside from the other small to medium sized trees. The trees in the K. Ketura orchard are in the base of the Arava Valley and subject to strong gusts of wind, sandstorms, and large amounts of solar radiation, despite being surrounded by other larger trees. There is also the possibility of future plans to install a climate monitoring station in the orchard, which would give more precise descriptions of the characteristics in this section of the orchard.

While hand pollinating the two trees with flowers, ants were observed covering the flowers of the tree and also pollinating, so the efficacy of the hybridization strategy was comprised. The observation of ants serving as pollinators in the orchard reflects the field investigations in Oman which noted multiple families of the hymenoptera order living on and pollinating the $B$. sacra trees there (Strumia et al, 2007). Further research can be conducted to more rigorously engage in hybridization efforts which may increase the genetic diversity of the offspring and increase the percentage of seeds with embryos if that indeed is a factor in the dearth of viable seeds.

The collection and planting of the seeds of flowers pollinated by the pollen of $B$. nana will indicate whether or not hybridization in this case had a beneficial effect on seed viability. When the seedlings in the K. Ketura greenhouse are mature enough, some will be planted in the orchard, others will be given to farms at higher elevations in Israel, such as K. Naot Smadar, K. Sde Boker (480 m a.s.I), and Wadi Atir (375 m a.s.l) to be cultivated and observed in those conditions. This strategy may yield further clues and such factors as the presence or absence of specific pollinators, temperature gradients and the effects of microclimate seasonality can be more precisely determined. The appropriate tests will continue to be applied in future seed planting at K. Ketura and the information about the effectiveness of various strategies to increase the germination rate and the genetic resources of the Boswellia trees will be disseminated to interested parties elsewhere via publication in journals and other channels of communication.

\section{Conclusion}

The low rate of germination of Boswellia sacra seeds is not due to a genetic bottleneck and cannot be attributed to tapping. In this study none of the trees were tapped.

However the different germination rates between the tree at Kibbutz Ketura and the identical tree at Naot Smadar were profound enough to indicate that the challenge to seed viability is primarily environmental. 
Possibly critical elements include temperature, soil fertility, absence or presence of pollinators, solar exposure and indicate a clear connection to the altitude at which the tree is grown. Further experimentation may reveal which of the factors encourages the formation of viable embryos and thus allows for a healthier germination rate.

\section{REFERENCES}

Bowen MR, 1988. A survey of tree planting in Somalia 1925-1985. No. 36. Oxford Forestry Institute, University of Oxford.

Coppi A, Cecchi L, Selvi F, Raffaelli M, 2010. The Frankincense tree (Boswellia sacra, Burseraceae) from Oman: ITS and ISSR analyses of genetic diversity and implications for conservation. Genet Resour Crop Evol, 57(7): 1041-1052.

Eslamieh J, 2010. Creating "Perfect" Boswellia." Cactus Succulent J, 82(3): 126-131.

Eslamieh J, 2011. Cultivation of Boswellia: Sacred Trees of Frankincense ; a Book on the History, Cultivation, Original Descriptions, Staging, Hybridization, Holistic Use, and Future of Boswellias in Our World (Phoenix, AZ: Book's Mind 2011).

Lemenih $M$, Teketay $D, 2004$. Integrating natural gum and resin production with biodiversity conservation and desertification control and adapting to climate change in drylands of Ethiopia. National Workshop on Non-Timber Forest Products in Ethiopia, 1, Addis Abeba (Ethiopia), 5-6 Apr 2004, Ethiopian Agricultural Research Organization,.

Mosti S, Raffaelli M, Tardelli M, 2012. Contribution to the flora of central-southern Dhofar (Sultanate of Oman). Webbia, 67(1): 65-91.

Navdeep Bansal SM, Kalra S, Khann D, 2013. Boswellia serrata Frankincense a Jesus gifted herb: an updated pharmacological profile. Pharmacologia, 4(6): 457-63.

Negussie A, Aerts R, Gebrehiwot K, Muys B, 2008. Seedling mortality causes recruitment limitation of Boswellia papyrifera in northern Ethiopia. J Arid Environ, 72(4): 378-383.

Raffaelli M, Mosti S, Tardelli M, 2003. The Frankincense tree (Boswellia sacra Flueck., Burseraceae) in Dhofar, southern Oman: field-investigations on the natural populations. Webbia, 58(1): 133149.

Raffaelli M, Mosti S, Tardelli M, 2006. Boswellia sacra Flueck. (Burseraceae) in the Hasik area (Eastern Dhofar, Oman) and a list of the surrounding flora. Webbia, 61(2): 245-251.

Strumia F, Dapporto L, Dellacasa M, Scaramozzino PL, 2007. Notes on some insects associated to frankincense tree (Boswellia sacra fluckiger 1867 Burseraceae) in Dhofar (sultanate of Oman). Atti Soc. Tosc Sci Nat Mem Serie B, 114: 135-139.

World Heritage, 2000. World Heritage Committee Inscribes $61 \mathrm{New}$ Sites on World Heritage List. UNESCO World Heritage Centre. 30 Nov. 2000. Web. 01 June 2016.
Citation: Swartout BT, Solowey E, 2018. Increasing Boswellia sacra seeds' germination viability and genetic variability utilizing various methods. Net J Agric Sci, 6(3): 29-34. 